9 Rodgers B. Socio-economic status, employment and neurosis. Soc Psychiatry Psychiatr Epidemiol 1991;26:104-14.

10 Blazer DG, Kessler RC, McGonagle KA, Swartz MS. The prevalence and distribution of major depression in a national community sample: the national comorbidity survey. Am J Psychiatry 1994;151:979-86.

11 Weich S, Lewis G. Material standard of living, social class and the prevalence of the common mental disorders in Great Britain. J Epidemiol Community Health 1998;52:8-14.

12 Bruce ML, Takeuchi DT, Leaf PJ. Poverty and psychiatric status. Arch Gen Psychiatry 1991;48:470-4.

13 Murphy JM, Olivier DC, Monson RR, Sobol AM, Federman EB, Leighton AH. Depression and anxiety in relation to social status. Arch Gen Psychiatry 1991;48:223-9.

14 Romans SE, Walton VA, McNoe B, Herbison GP, Mullen PE. Otago women's health survey 30 month follow-up. II: remission patterns of non-psychotic psychiatric disorder. BrJ Psychiatry 1993;163:739-46.

15 Weich S, Churchill R, Lewis G, Mann A. Do socio-economic risk factors predict the incidence and maintenance of psychiatric disorder in primary care? Psychol Med 1997;27:73-80.
16 Warr P. Work, unemployment and mental health. Oxford: Oxford Science, 1987

17 Fergusson DM, Horwood LJ, Lynskey MT. The effects of unemploymen on psychiatric illness during young adulthood. Psychol Med 1997;27: $371-81$.

18 Turner JB. Economic context and the health effects of unemployment. $J$ Health Soc Behav 1995;36:213-29.

19 Taylor MF, (ed), Brice J, Buck N, Prentice E. British household panel survey user manual volume A: introduction, technical report and appendices. Colchester: University of Essex, 1995

20 Goldberg DP, Williams P. The user's guide to the general health questionnaire Nfer-Nelson: Windsor, 1988

21 Stansfeld SA, Marmot MG. Social class and minor psychiatric disorder in civil servants: a validated screening survey using the general health questionnaire. Psychol Med 1992:29:739-49.

22 Huber PJ. Robust statistics. New York:John Wiley, 1981.

23 Weich S. Prevention of the common mental disorders: a public health perspective. Psychol Med 1997;27:757-64.

\title{
Underreporting of suspected adverse drug reactions to newly marketed ("black triangle") drugs in general practice: observational study
}

\author{
Richard M Martin, Karan V Kapoor, Lynda V Wilton, Ronald D Mann
}

Data on side effects of newly launched drugs are limited, ${ }^{1}$ highlighting the need for effective postmarketing surveillance. An inverted black triangle $(\boldsymbol{\nabla})$ on product literature identifies new products. Suspected adverse reactions to these drugs, however minor, should be reported to the Committee on Safety of Medicines through the yellow card scheme. ${ }^{2}$ Adverse reactions are underreported, ${ }^{3}$ and few doctors in the United Kingdom know the meaning of the "black triangle" symbol. ${ }^{4}$ We assessed the degree of underreporting of suspected adverse reactions to new drugs in general practice and determined if reporting varied when reactions were severe or previously unrecognised.

\section{Patients, methods, and results}

The Drug Safety Research Unit performs observational cohort studies (prescription event monitoring) on selected newly marketed drugs in general practice All patients in England who have been dispensed selected new drugs are identified for these studies by the Prescription Pricing Authority. Questionnaires ("green forms") are subsequently sent to prescribers asking about clinical events, suspected adverse drug reactions, and events reported to the Committee on Safety of Medicines as suspected adverse reactions. For the 10 drugs we examined (acarbose, risperidone, fluvastatin, tramadol, gabapentin, famciclovir, lansoprazole, zolpidem, venlafaxine, and losartan) median exposure was 46435 (interquartile range 24524 to $55735)$ patient months. Events recorded by general practitioners as suspected adverse reactions, and those stated as having been reported to the Committee on Safety of Medicines, were classified as serious or nonserious, using the definition published in the British National Formulary. ${ }^{2}$ We determined whether the event was listed ("labelled") in the summary of product characteristics at the time of the study; events not listed were classified as unlabelled. Reports stating "non-specific side effects" or intolerance were not classified. By calculating a risk ratio, using non-serious labelled events as the reference group, we determined the likelihood of each category of adverse reaction being reported to the Committee on Safety of Medicines.

There were 3045 events (in 2034 patients) reported as suspected adverse reactions on the green forms during the 10 studies. General practitioners indicated that they had reported $275(9.0 \%$; $95 \%$ confidence interval $8.0 \%$ to $10.0 \%$ ) of these reactions to the Committee on Safety of Medicines: reporting was highest for serious unlabelled reactions (26/81; $32.1 \%)$ and lowest for non-serious labelled reactions $(94 / 1443 ; 6.5 \%)$ (table). Serious unlabelled and non-serious unlabelled reactions were significantly more likely to be reported than were non-serious labelled reactions. According to general practitioners responses, the proportion of serious labelled reactions also reported on yellow cards $(7 / 64 ; 10.9 \%)$ was only slightly greater than that of non-serious labelled reactions.

\section{Drug Safety Southampton SO31 1AA Richard M Martin, clinical research fellow Karan V Kapoor, research assistant}

School of Medicine, Faculty of Medicine, Health and Biological Sciences, University of Southampton, Southampton S016 7PX

Lynda V Wilton, visiting honorary lecturer

Ronald D Mann, senior professorial fellow

Correspondence to: Dr Martin drmann@dsru. u-net.com

BMJ 1998;317:119-20

Suspected adverse drug reactions reported by general practitioners on green forms for 10 newly marketed "black triangle" drugs during prescription event monitoring studies 1994-7

\begin{tabular}{lccc} 
& \multicolumn{2}{c}{ Adverse drug reactions } & \\
\cline { 2 - 3 } Type of adverse reaction & $\begin{array}{c}\text { No stated on } \\
\text { green form }\end{array}$ & $\begin{array}{c}\text { No (\%) also reported to } \\
\text { Committee on Safety } \\
\text { of Medicines }\end{array}$ & Risk ratio (95\% Cl) \\
\hline Non-serious: & 2400 & $235(9.8)$ & - \\
\hline Labelled & 1443 & $94(6.5)$ & Reference \\
\hline Unlabelled & 957 & $141(14.7)$ & $2.3(1.8 \text { to } 2.9)^{\star}$ \\
\hline Serious: & 145 & $33(22.8)$ & $3.5(2.4 \text { to } 5.0)^{*}$ \\
\hline Labelled & 64 & $7(10.9)$ & $1.7(0.8$ to 3.5) \\
\hline Unlabelled & 81 & $26(32.1)$ & $4.9(3.4 \text { to } 7.2)^{\star}$ \\
\hline Not categorised & 500 & $7(1.4)$ & - \\
\hline Total & 3045 & $275(9.0)$ & - \\
\hline
\end{tabular}

${ }^{*} \mathrm{P}<0.0001$.

†Insufficient information available for an assessment of severity or of status as labelled or unlabelled. 


\section{Comment}

These findings show a selective reporting bias to the Committee on Safety of Medicines, with general practitioners notifying a greater proportion of adverse reactions that are of greatest clinical concern. Our estimates are subject to potential reporting and recall biases. Some doctors who had submitted a yellow card may not have completed the green form. We would have underestimated the proportion of yellow cards submitted if green form responders were less likely to complete yellow cards than green form nonresponders. It seems more plausible that green form responders would be at least as likely to report yellow cards as green form non-responders. Doctors may not have indicated that a yellow card was submitted. As the number of yellow cards reported per doctor is low, the impact of recall bias on our estimates is probably limited. Our overall estimate of underreporting corresponds to previous estimates. ${ }^{5}$ The message that doctors should submit yellow cards for all suspected adverse drug reactions to "black triangle" drugs should be reinforced.

We thank the general practitioners who take part in prescription-event monitoring studies. We also thank Shayne
Freemantle and Gillian Pearce for technical help with accessing the data.

Contributors: RMM was involved in formulating the study hypothesis, executing and coordinating the study, study design, analysis and interpretation of data, and writing the paper. KVK was involved in interrogating the prescription-event monitoring database and preparing the data for analysis and contributed to the writing of the paper. LVW was involved in study design, discussion of core ideas, quality control, and interpretation of data and contributed to the writing of the paper. RDM initiated the research project, discussed core ideas, helped formulate the study hypothesis, participated in study design, was involved in interpretation of results, and edited the paper. RDM will act as guarantor.

Funding: None

Conflict of interest: None

Rawlins MD, Jefferys DB. United Kingdom product licence applications involving new active substances, 1987-1989: their fate after appeals. $B r$ I Clin Pharmac 1993;35.599-602.

2 Joint Formulary Committee. British national formulary. No 33. London: British Medical Association and Royal Pharmaceutical Society of Great Britain, 1997:10.

3 Bem JL, Mann RD, Rawlins MD. Review of yellow cards 1986 and 1987. BMJ 1988;296:1319.

4 Belton KJ, Lewis SC, Payne S, Rawlins MD, Wood SM. Attitudinal survey of adverse drug reaction reporting by medical practitioners in the United Kingdom. Br J Clin Pharmac 1995;39:223-6.

5 Lumley CE, Walker SR, Hall GC, Staunton N, Grob P. The under-reporting of adverse drug reactions seen in general practice. Pharmaceut Med 1986;1:205-12.

(Accepted 12 February 1998)

\section{Neglect of growth and development in the clinical monitoring of children and teenagers with inflammatory bowel disease: review of case records}

Subrata Ghosh, Hazel E Drummond, Anne Ferguson

Gastrointestinal Unit, Department of Medicine, Western General Hospital and University of Edinburgh, Edinburgh EH4 2XU Subrata Ghosh, consultant gastroenterologist Hazel E

Drummond, research associate

Anne Ferguson, professor of gastroenterology

Correspondence to: Professor Ferguson anne.ferguson@ ed.ac.uk

BMJ 1998;317:120-1
Failure of growth and retarded sexual development are serious and common problems in children and teenagers with inflammatory bowel disease, particularly Crohn's disease. Thus height, weight, sexual staging, and bone age should be closely monitored in such patients. In 1989 we reported serious underrecording of these variables of growth in a cohort of Scottish children with inflammatory bowel disease. ${ }^{1}$ We assessed the situation a decade later.

\section{Subjects, methods, and results}

We studied 28 boys and 13 girls aged $\leqslant 16$ years at first admission to hospital with ulcerative colitis $(n=14)$ or Crohn's disease $(n=27)$. These patients, identified from the Scottish hospitals database of inpatients statistics for 1984-88, were resident in four of the Scottish regions.

We reviewed the patients' case records and noted whether height, weight, bone age, and sexual development were recorded. The frequencies of recording of these variables of growth were analysed by specialty of consultant. Since $14(34 \%)$ of the patients were attending one consultant's (A) clinic, the frequencies of recording by this consultant were considered separately.
The table summarises the results. With the exception of consultant A, gastroenterologists, physicians, and surgeons made few recordings of height, and very few recordings of bone age or sexual development were made by any specialty, including paediatricians.

\section{Comment}

The causes of Crohn's disease and ulcerative colitis are unknown, but abundant evidence supports the clinical illness as being a composite effect of several variables both symptomatic and indolent. These include inflammatory disease activity, side effects of drugs, psychological distress, destructive ulceration, bone demineralisation, and growth failure. Growth failure is not confined to patients of paediatricians as growth and sexual maturation of young people with Crohn's disease often continue until age 20 or later. Despite this, few consultants in adult medicine or surgery record the physical development of teenage patients; perhaps the doctor assumes nothing specific can be done about growth failure, or this neglect may simply be an oversight.

We do not know if such neglect is unique to gastroenterologists, or whether similar findings would have emerged from studying the case records of teenagers with cancer, renal failure, asthma, rheumatic diseases, 